\title{
Dose-response relationship between physical activity and mortality in adults with noncommunicable diseases: a systematic review and meta-analysis of prospective observational studies
}

\author{
Wolfgang Geidl ${ }^{1 *}$ (D), Sabrina Schlesinger ${ }^{2}$, Eriselda Mino ${ }^{1}$, Lorena Miranda ${ }^{1}$ and Klaus Pfeifer ${ }^{1}$
}

\begin{abstract}
Background: This study aims to investigate the relationship between post-diagnosis physical activity and mortality in patients with selected noncommunicable diseases, including breast cancer, lung cancer, type 2 diabetes, ischemic heart disease, stroke, chronic obstructive pulmonary disease (COPD), osteoarthritis, low back pain and major depressive disorder.

Methods: A systematic search was conducted of PubMed, Scopus and the Web of Science from their inception to August 2018. Additionally, the search was updated in August 2019. Eligibility criteria included prospective observational studies examining the relationship between at least three physical activity categories (e.g. low, moderate, high) and all-cause mortality as the primary outcome.

Results: In total, 28 studies were included in the meta-analysis: 12 for breast cancer, 6 for type 2 diabetes, 8 for ischemic heart disease and 2 for COPD. The linear meta-analysis revealed that each 10 metabolic equivalent task hours increase of physical activity per week was associated with a 22\% lower mortality rate in breast cancer patients (Summary Hazard Ratio [HR], 0.78; 95\% Cl: 0.71, 0.86; $I^{2}: 90.1 \%$ ), 12\% in ischemic heart disease patients (HR, $\left.0.88 ; 95 \% \mathrm{Cl}: 0.83,0.93 ; \mathrm{I}^{2}: 86.5 \%\right), 30 \%$ in COPD patients (HR, 0.70; 95\% Cl: $\left.0.45,1.09 ; I^{2}: 94 \%\right)$ and $4 \%$ in type 2 diabetes patients (HR, 0.96; $\left.95 \% \mathrm{Cl}: 0.93,0.99 ; I^{2}: 71.8 \%\right)$. There was indication of a non-linear association with mortality risk reductions even for low levels of activity, as well as a flattening of the curve at higher levels of activity. The certainty of evidence was low for breast cancer, type 2 diabetes and ischemic heart disease but only very low for COPD.

Conclusion: Higher levels of post-diagnosis physical activity are associated with lower mortality rates in breast cancer, type 2 diabetes, ischemic heart disease and COPD patients, with indication of a no-threshold and non-linear dose-response pattern.
\end{abstract}

Keywords: Physical activity, Health promotion, Public health, Non-communicable disease, Longevity

\footnotetext{
* Correspondence: wolfgang.geidl@fau.de

'Department of Sport Science and Sport, Division Exercise and Health,

Friedrich-Alexander University Erlangen-Nürnberg, Gebbertstraße 123b, 91058 Erlangen, Germany

Full list of author information is available at the end of the article
}

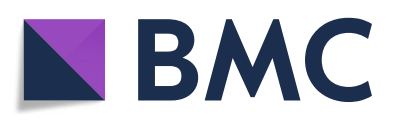

( ) The Author(s). 2020 Open Access This article is licensed under a Creative Commons Attribution 4.0 International License, which permits use, sharing, adaptation, distribution and reproduction in any medium or format, as long as you give appropriate credit to the original author(s) and the source, provide a link to the Creative Commons licence, and indicate if changes were made. The images or other third party material in this article are included in the article's Creative Commons licence, unless indicated otherwise in a credit line to the material. If material is not included in the article's Creative Commons licence and your intended use is not permitted by statutory regulation or exceeds the permitted use, you will need to obtain permission directly from the copyright holder. To view a copy of this licence, visit http://creativecommons.org/licenses/by/4.0/. The Creative Commons Public Domain Dedication waiver (http://creativecommons.org/publicdomain/zero/1.0/) applies to the data made available in this article, unless otherwise stated in a credit line to the data. 


\section{Background}

Physical activity has been proposed as a form of treatment for people with noncommunicable diseases (NCDs) [1]. Regular physical activity positively influences symptoms and comorbidities, physical fitness and health-related quality of life in more than 25 NCDs, including osteoarthritis, type 2 diabetes (T2D), stroke and clinical depression [1]. However, it is less clear whether higher levels of physical activity in adults with NCDs also reduce mortality rates and thus lead to longer life expectancies.

The current evidence for the general population regarding physical activity and mortality is comprehensive and unambiguous. Numerous large cohort studies have consistently demonstrated an inverse relationship between physical activity levels and mortality [2]. Meta-analyses with pooled data from these studies produce similar findings $[3,4]$. Compared with the lower physical activity groups, the risk of premature death was remarkably reduced in the higher physical activity groups. The metaanalysis conducted by Samitz et al. [4] revealed that per 1 hour increment of moderate-intensity physical activity per week, the relative risk of mortality was reduced by $4 \%$. In the updated physical activity guidelines for healthy adults from the U.S. Department of Health and Human Services [5], a clear dose-response association between the volume of physical activity and mortality rates has been shown. The shape of the dose-response curve is characterized by a regressive, non-linear effect, where the greatest difference in mortality rates occurs among inactive and minimally active individuals. For higher physical activity levels, the dose-response curve flattens out. This means that the relative risk of mortality continues to decline with higher volumes of physical activity with no adverse effects on mortality, even at very high levels of physical activity [5].

In adults with NCDs, the current evidence on dose-response relations between physical activity and mortality is considerably weaker and inconsistent. For T2D, the meta-analysis conducted by Kodama et al. [6] found that an increment of one MET (metabolic equivalent task) h/ day of physical activity was associated with a 9.5\% relative risk reduction in all-cause mortality, thereby suggesting that post-diagnosis physical activity levels may result in similar mortality risk reductions compared to the general population. In a meta-analysis for patients with cancer, comparably beneficial associations between physical activity and mortality rates were reported by $\mathrm{Li}$ et al. [7]. Moore et al. [8] pooled data from six cohort studies and concluded that the longevity effects of physical activity vary according to the preexisting NCDs, with higher benefits of regular physical activity in terms of life expectancy for those with a history of cancer $(7.0 \mathrm{y})$ and heart disease $(6.2 \mathrm{y})$ compared to those without these diseases (3.7 y) [8]. Current evidence from the US Physical Activity Guidelines Advisory Committee [9] reported a general relationship between higher post-diagnosis physical activity and lower mortality rates in five NCDs (breast or colorectal or prostate cancer, hypertension and T2D). However, the committee found few studies that have systematically quantified the dose-response relations between physical activity levels and mortality end-points in people with preexisting NCDs. Accordingly, their report concludes that dose-response relationships cannot yet be defined for adults with NCDs [9].

Thus, the objective of this study was to conduct a systematic review and dose-response meta-analysis of physical activity and mortality in people with selected NCDs. We aimed to define the dose-response relationship between post-diagnosis physical activity and mortality rates for nine NCDs with a high global burden of disease [10], including low back pain, T2D, osteoarthritis, depressive disorder, chronic obstructive pulmonary disease (COPD), breast cancer, lung cancer, stroke and ischemic heart disease (IHD).

\section{Methods}

The method for this systematic review and meta-analysis was predefined in a published study protocol [11], and registered at PROSPERO - the International Prospective Register of Systematic Reviews (registration number: CRD42018103357; available online at https://www.crd. york.ac.uk/prospero/display_record.php?RecordID=10335 7). This systematic review and meta-analysis is reported in compliance with the Preferred Reporting Items for Systematic Reviews and Meta-Analyses (PRISMA) Statement for Reporting Systematic Reviews and Meta-Analysis (see Supplementary file 1) [12].

\section{Search and data sources}

A systematic search was conducted on PubMed, Scopus and the Web of Science from their inception to August 2018. This search was followed by a hand-search of the citations in the detected articles. The search was updated in August 2019 by using the forward citation search in Google Scholar for the articles that qualified for inclusion (see Supplementary file 2).

\section{Study selection}

The eligibility criteria required the population to consist of adults with a physician-confirmed or self-reported diagnosis of one of the nine NCDs (osteoarthritis, low back pain, depressive disorder, IHD, T2D, stroke, COPD, lung cancer or breast cancer). Studies that investigated the association between physical activity and all-cause mortality as the primary outcome or any other indication-specific mortality as a primary or secondary outcome were included. To calculate the dose-response meta-analysis, at least three categories of the exposure (i.e. physical activity) had to be reported in the original study. The eligible study 
design was that of a prospective observational nature. Non-English-language records, studies conducted on nonhuman subjects and duplicate data sets were not considered. No limit on publication year was imposed.

First, the literature identified through the electronic search was primarily assessed for eligibility by inspecting the titles and abstracts. We decided to divide the literature between three reviewers because of the large number of hits. Two additional reviewers were appointed to ensure the quality of the first screening process. In the second step, the full texts of the qualified studies were retrieved and critically evaluated for their final inclusion in the data collection process. The three reviewers independently assessed the articles for eligibility, and any discrepancies were resolved by discussions and when necessary, by adjudication from another reviewer.

\section{Data collection and items}

The following details were extracted from the included publications: first author, year of publication, study name, design, country, mean follow-up time, total sample size, age, sex, mortality cases in total and per physical activity category, exposure categories, diagnosis and mortality ascertainment, relative risks and corresponding 95\% CIs of the multivariate-adjusted models. Thirteen authors of the selected studies were contacted for additional data on physical activity. However the original data from two authors did not allow for an estimation of physical activity levels in MET-h/week (meaning that these studies were excluded), and two authors provided information on physical activity dosage $[13,14]$.

\section{Risk of bias in individual studies}

The Cochrane tool for assessing the "Risk Of Bias In Nonrandomised Studies - of Interventions" (ROBINS-I) was used to estimate the risk of bias and endorse conclusions closer to the truth [15]. The tool includes seven domains that lead to the risk of bias. These domains are due to 1 ) confounding, 2) selection of participants, 3) exposure assessment, 4) misclassification during follow-up, 5) missing data, 6) measurement of the outcome, and 7) selective reporting of results. The domains 1,2 and 3 are directly considered in rating the certainty of evidence. The included studies were independently evaluated by two assessors (EM, LM). Any inconsistencies in the evaluations were documented and then discussed with a third member of the research team (WG) and resolved by mutual agreement.

\section{Statistical analysis}

The meta-analysis was performed using Stata statistical software (Version 15, StataCorp, College Station, TX, US). We pooled aggregated data using the random effects meta-regression model, as suggested by DerSimonian and Laird [16], assuming random variance of the true effect of physical activity among studies, especially due to diversity in assessment methods. For studies that reported results from one cohort in stratified estimates (e.g. separately for men and women), a fixed effect model was used to combine the effects for the whole cohort and include it in the meta-analysis. We conducted the linear dose-response association between physical activity per $10 \mathrm{MET}$-h/week and all-cause mortality via the method used by Greenland and Longnecker and presented via forest plots [17, 18]. For this analysis, the number of cases and person-years, the quantification of the exposure and RRs with the corresponding 95\% CIs of at least three categories were needed. If information was missing, the distributions of cases and person-years were estimated using the total number of cases and the total number of participants plus the follow-up period, as previously described [19]. If the lowest category was not used as a reference, the reported risk estimates were recalculated using Orsini et al.'s [20] method to ensure comparability. The data on the volume of physical activity were converted into a unit of MET-h/week. If a study reported the exposure categories as ranges, then for each category, the midpoint between the lower and upper limit was calculated. For open categories, we assumed that the width was the same as the adjacent category. A potential nonlinear association was evaluated using a restricted cubic spline model with three knots at the 10th, 50th and 90th percentile of frequency of the exposure [18]. The indication of nonlinearity was tested using a likelihood ratio test.

The heterogeneity was described using the measure of inconsistency $\left(\mathrm{I}^{2}\right)$, and $\operatorname{tau}^{2}$ was used to measure the variance between the included studies [21]. Subgroup analysis and meta-regression were performed to explore the heterogeneity across studies. The analyses were stratified by demographic variables (age, geographic area), follow-up duration $(<10$ and $\geq 10$ years), death cases $(<100,100$ 500 and $\geq 500$ ), method of physical activity assessment (questionnaire and interview), risk of bias (moderate and serious) and additional disease-specific relevant factors (e.g. menopausal status in breast cancer). Publication bias was investigated through various visual and statistical tools, including funnel plots and Egger's test for smallstudy effects, where asymmetry with a significance level of $p<0.1$ suggests publication bias $[22,23]$.

\section{Certainty of evidence}

We used the Grading of Recommendations, Assessment, Development and Evaluation (GRADE) approach to assess the certainty of evidence [24]. GRADE includes four certainty categories (very low, low, moderate or high) and we worked with GRADE profiler (GRADEPRO) to present the overall certainty of evidence for the outcome of interest based on the included studies [25]. One reviewer assessed the certainty of evidence and a second 
reviewer revised the certainty assessments as necessary. Due to the inherent limitations in observational studies, certainty of evidence starts at low and can be further downgraded (based on risk of bias, imprecision, inconsistency of results, indirectness of evidence and publication bias) or upgraded (based on large magnitude of effect, a dose-response gradient, or opposing residual confounding) [26]. Following the GRADE recommendations for informative statements to communicate the findings we developed summary of findings tables and included plain language summaries based on effect magnitude and certainty of evidence in the result section [27].

\section{Results}

The systematic database search yielded 44,518 publications in total. Three additional studies were identified from the reference lists. Full texts were retrieved and screened for 183 articles with the potential for inclusion. Twenty-eight studies satisfied the inclusion criteria for only four out of the nine NCDs: breast cancer $(n=12), \operatorname{T} 2 \mathrm{D}(n=6), \operatorname{IHD}(n=8)$ and $\operatorname{COPD}(n=2)$ (see Fig. 1 for a detailed flow diagram).

\section{Study characteristics}

The 28 included studies were all published during the past two decades and based in numerous countries throughout the world. Out of these, 25 studies were prospective cohort studies, 2 prospective follow-ups to casecontrol studies and 3 follow-up studies of RCTs [13, 28, 29]. The sample sizes varied considerably from 435 [30] to 15,645 [31], with a total of 27,248 participants diagnosed with breast cancer, 32,221 with T2D, 4784 with COPD and 42,027 with IHD.

The follow-up duration ranged from 3.3 years [32] to 18.4 years [33]. A summary of the main characteristics of the cohorts is displayed in Table 1 . All-cause mortality was reported as the primary outcome in all included studies. Other reported outcomes were breast cancer mortality, recurrence and new primary events, cardiovascular disease mortality, IHD mortality and respiratory mortality. All exposure assessments of post-diagnosis physical activity were based on self- or intervieweradministered questionnaires. The time from diagnosis to physical activity measurement varied from three to 6 months post-diagnosis [48]. The longest follow-up was 14 years [53]. Detailed information on the measurement instruments for physical activity assessment can be found in Supplementary file 3. Exposure categories were presented as the volume of physical activity in MET-h/week [14, 28-32, 34-42, 44-46, 52], calorie expenditure [49], duration of physical activity [43], frequency of physical activity [51], and nominal categories [13, 33, 47, 48, 50, 53].

\section{Risk of bias in included studies}

In terms of the seven domains of ROBINS-I, no study had a low risk of bias. From the 28 publications assessed, eleven were evaluated to have a moderate risk of bias [13, 28, 30, 32, 35, 37, 46, 48-50, 53], and the remaining studies had a serious risk of bias. The main domains that introduced bias were 1) the confounding domain (mainly due to the lack of adjusting for potential confounders such as the level of physical activity before diagnosis) and 2) the domain of deviations from intended interventions. This point refers to the uncertainty as to whether the physical activity exposure measured at a given time in the observational studies is representative for the habitual activity levels of the individuals. It is important to note that all studies used validated measurement instruments (see Supplementary file 3) but due to the assessment of physical activity based on self-reports, a potential misclassification of physical activity could not be excluded. Therefore, $82 \%$ of the studies were rated with an unknown risk of bias in the domain of the classification of physical activity. The risk of bias for each domain in the 28 studies is shown in Fig. 2. In addition, Table 1 contains the final risk of bias evaluation across the studies, and Supplementary file 4 includes the detailed results of the risk of bias assessment. The overall certainty of evidence for the reduction of all-cause mortality germane to post-diagnosis physical activity is presented in Table 2.

\section{Post-diagnosis physical activity and all-cause mortality}

We examined the relationship between post-diagnosis physical activity and all-cause mortality in breast cancer, T2D, IHD and COPD populations. The results of the linear dose-response meta-analyses are presented in Fig. 3. Physical activity was associated with lower mortality rates in persons with breast cancer, T2D, COPD and IHD. For every $10 \mathrm{MET}$-h increase of physical activity per week, the summary hazard ratio (SHR) decreased by $22 \%$ in people with breast cancer (HR, 0.78; 95\% CI: 0.71, 0.86; $n=12)[28,30,32,34-42]$, by $12 \%$ in people with IHD (HR, 0.88; 95\% CI: 0.83, 0.93; $n=8)$ [13, 29, 48-53], and by $30 \%$ in people with COPD (HR, 0.70 ; $95 \% \mathrm{CI}: 0.45$, $1.09 ; n=2)[14,47]$. The mortality rates in people with T2D reduced by $4 \%$ for every 10 MET-h/week (HR, 0.96; 95\% CI: $0.93,0.99 ; n=6)$ [31, 33, 43-46]. Ten METhours/week is equivalent to $180 \mathrm{~min}$ of walking or $86 \mathrm{~min}$ of running [54]. These findings are based on a very low certainty of evidence for COPD, and low certainty of evidence for breast cancer, IHD, and T2D (see Table 2 and the GRADE evidence profile in Supplementary file 5).

There was evidence of high heterogeneity between the included studies for all the target groups, specifically breast cancer $\left(\mathrm{I}^{2}=90.1 \%\right)$, T2D $\left(\mathrm{I}^{2}=72.7 \%\right)$, IHD $\left(\mathrm{I}^{2}=\right.$ 


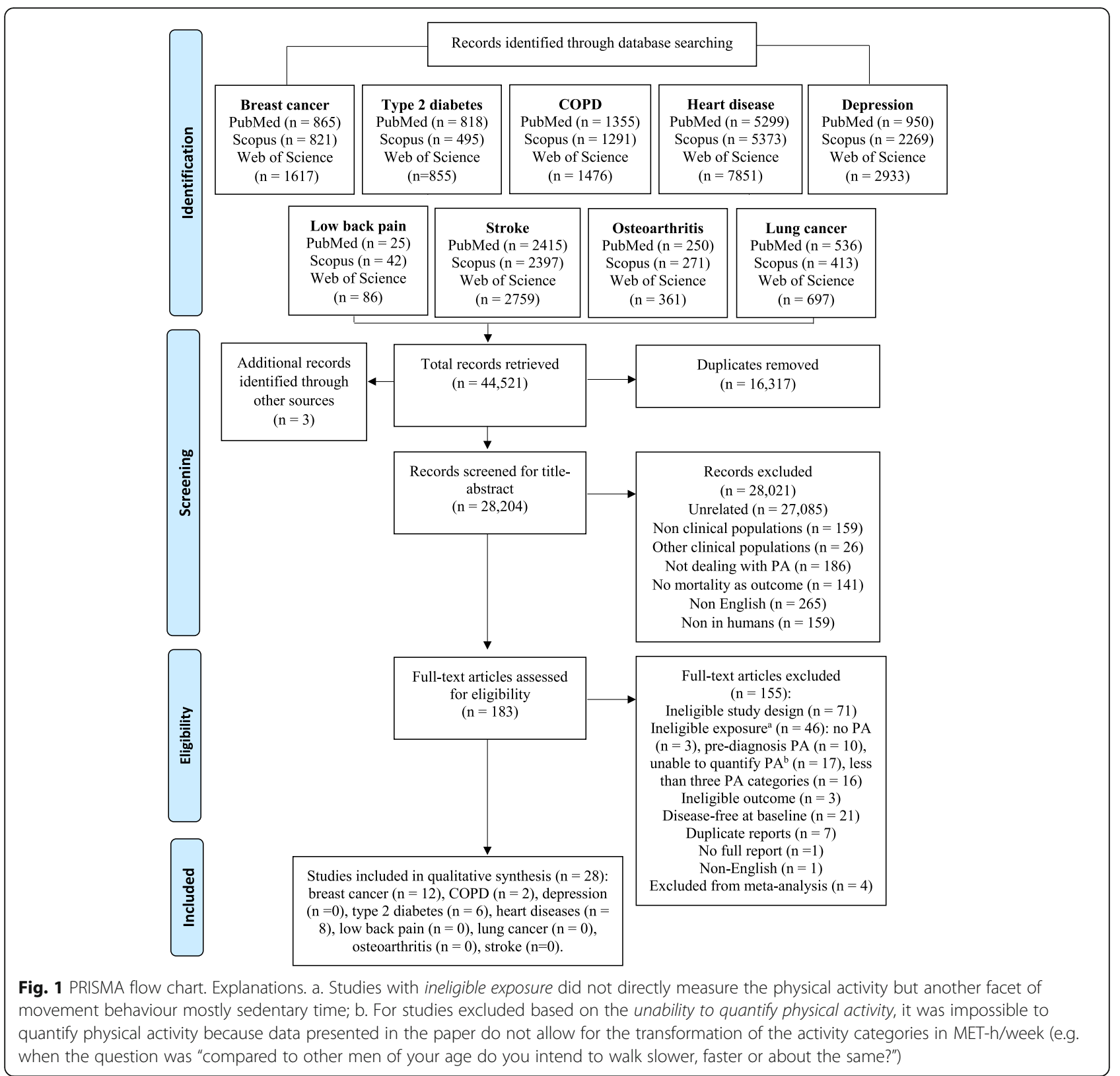

86.5\%) and COPD $\left(\mathrm{I}^{2}=94.0 \%\right)$. The subgroup analysis for breast cancer (Supplementary file 7, Table S7.1) highlighted that there are no differences regarding menopausal status, assessment of physical activity, geographical area, age or number of cases; however, the subgroup difference is statistically significant $(p=0.018)$ for the follow-up variable only, meaning that the length of follow up can modify the observed associations between physical activity and mortality. None of the other included variables (age, geographic area, death cases, method of physical activity assessment, risk of bias, menopausal status in breast cancer) explained the amount of between-study variance $(p>0.05)$.
The funnel plot for breast cancer as well as T2D did not suggest the presence of publication bias, and Egger's test confirmed that there was no apparent evidence of bias. However, the funnel plot for IHD studies was asymmetrical, and the test for small-study effects evidenced that publication bias could be present $(p<0.001)$ (Supplementary file 6). Asymmetry was represented by the lack of small studies with null findings.

Figure 4 presents the non-linear dose-response metaanalysis among the four NCD populations. The results for breast cancer $(n=12), \mathrm{T} 2 \mathrm{D}(n=6), \operatorname{IHD}(n=8)$ as well as $\operatorname{COPD}(n=2)$ indicated a non-linear dose-response relationship between post-diagnosis physical 


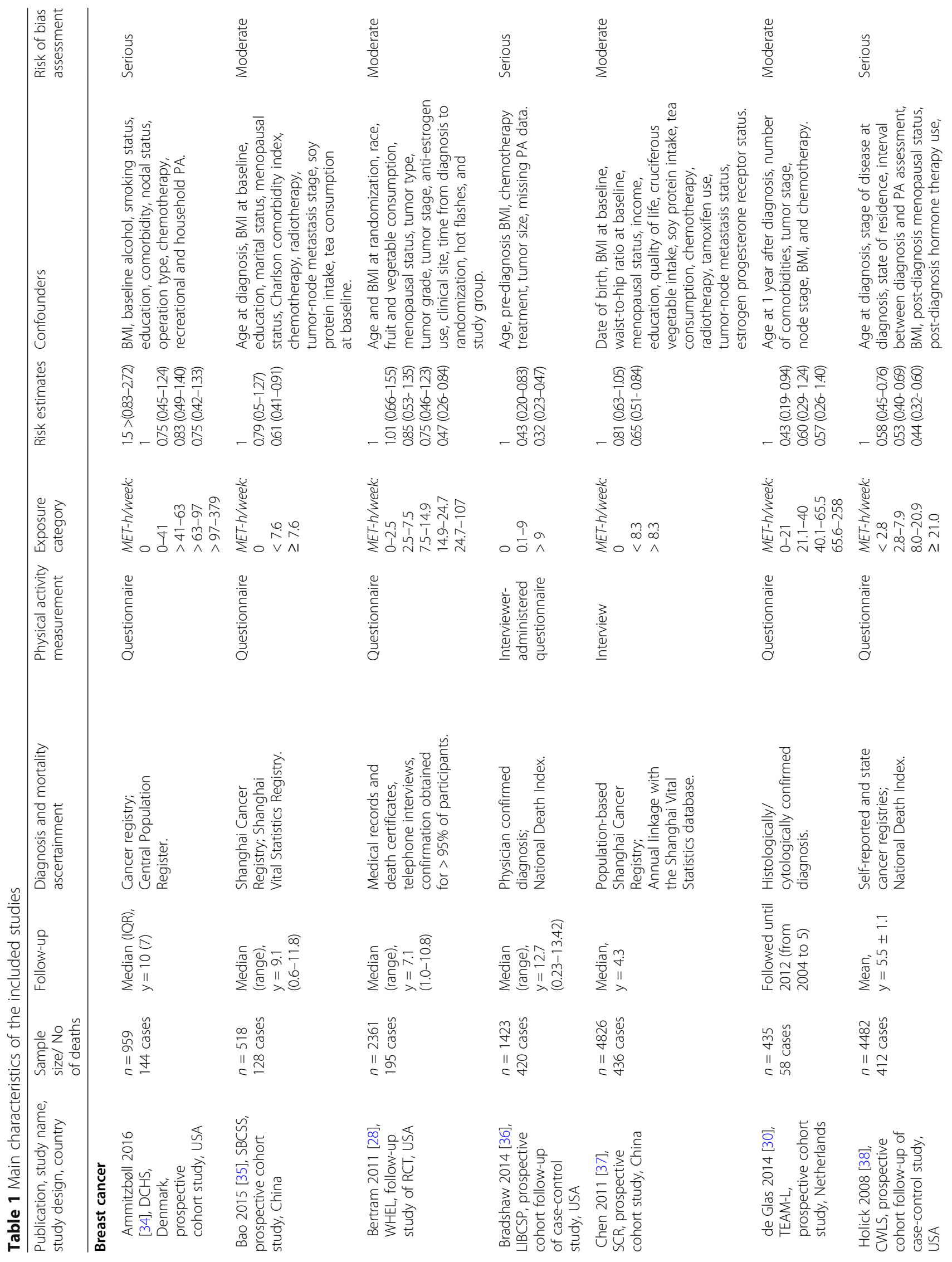




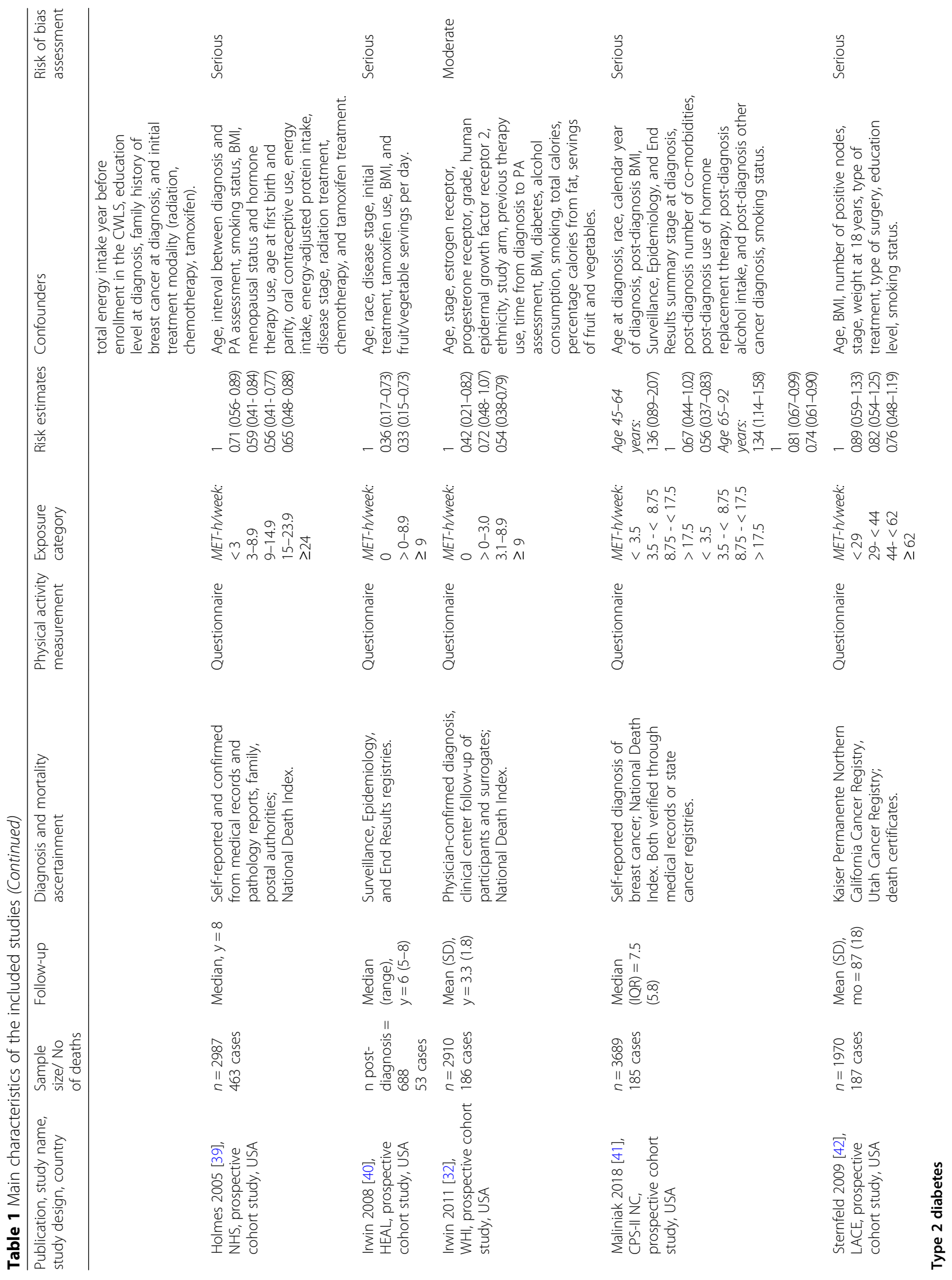




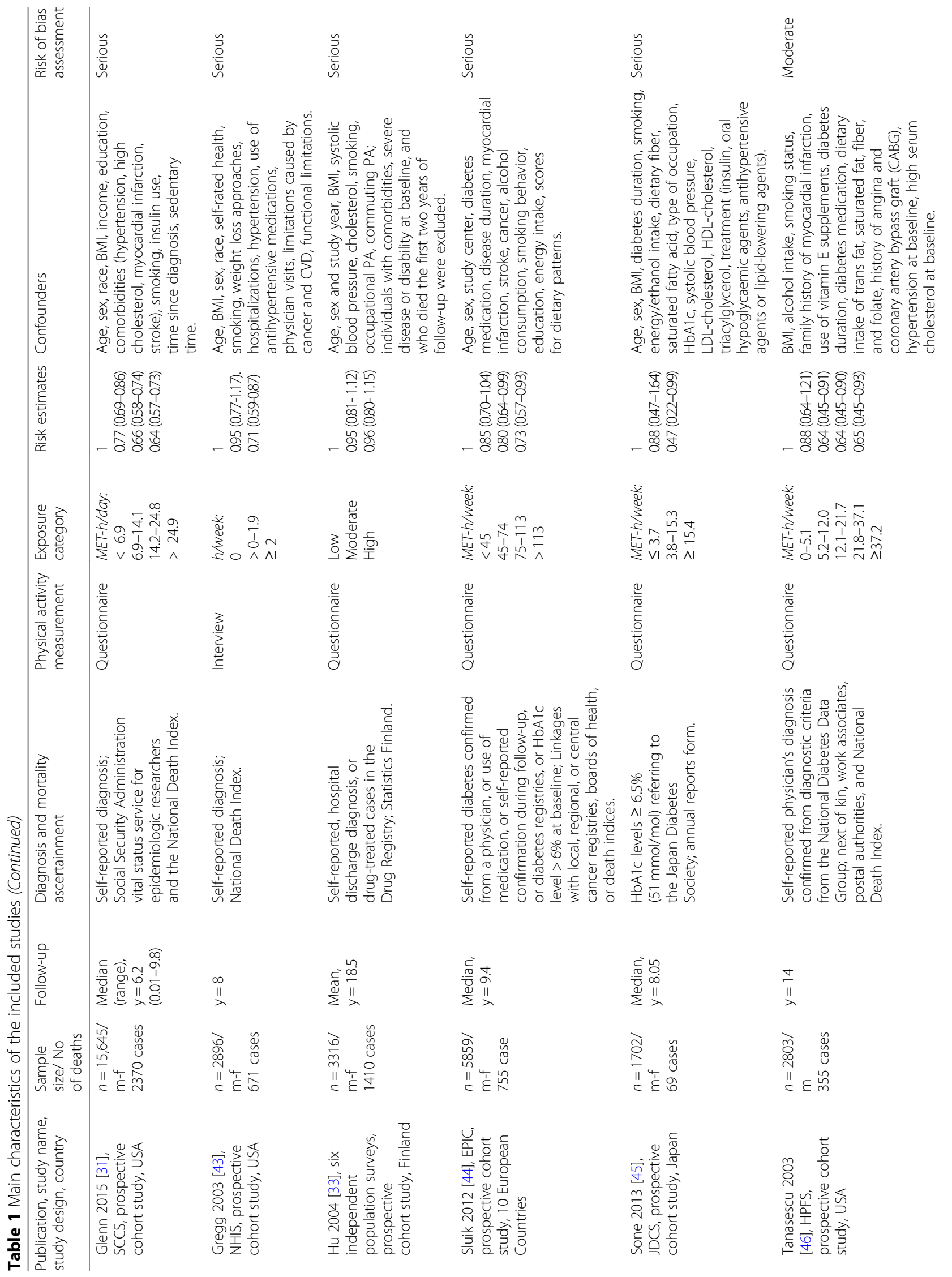




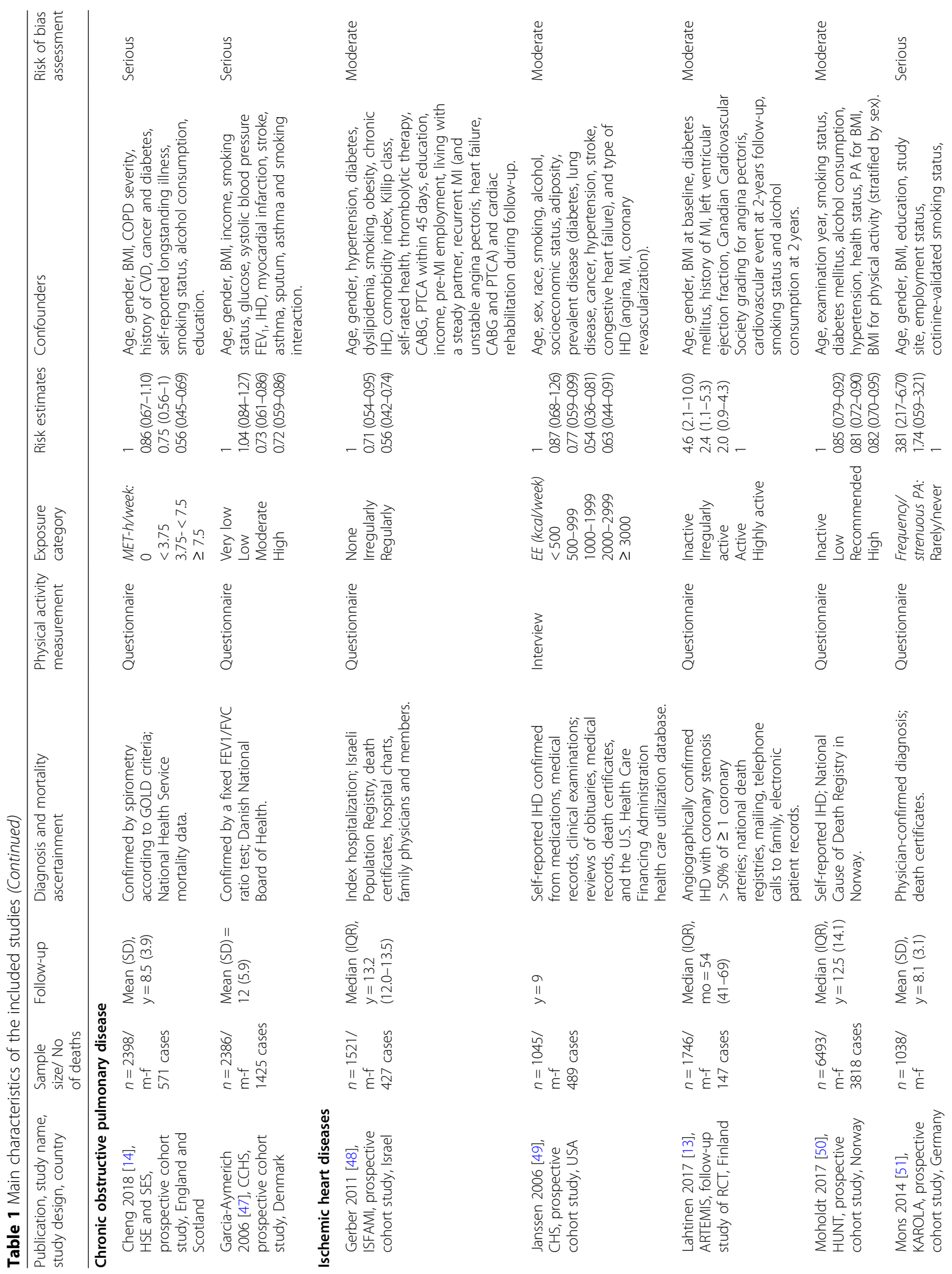




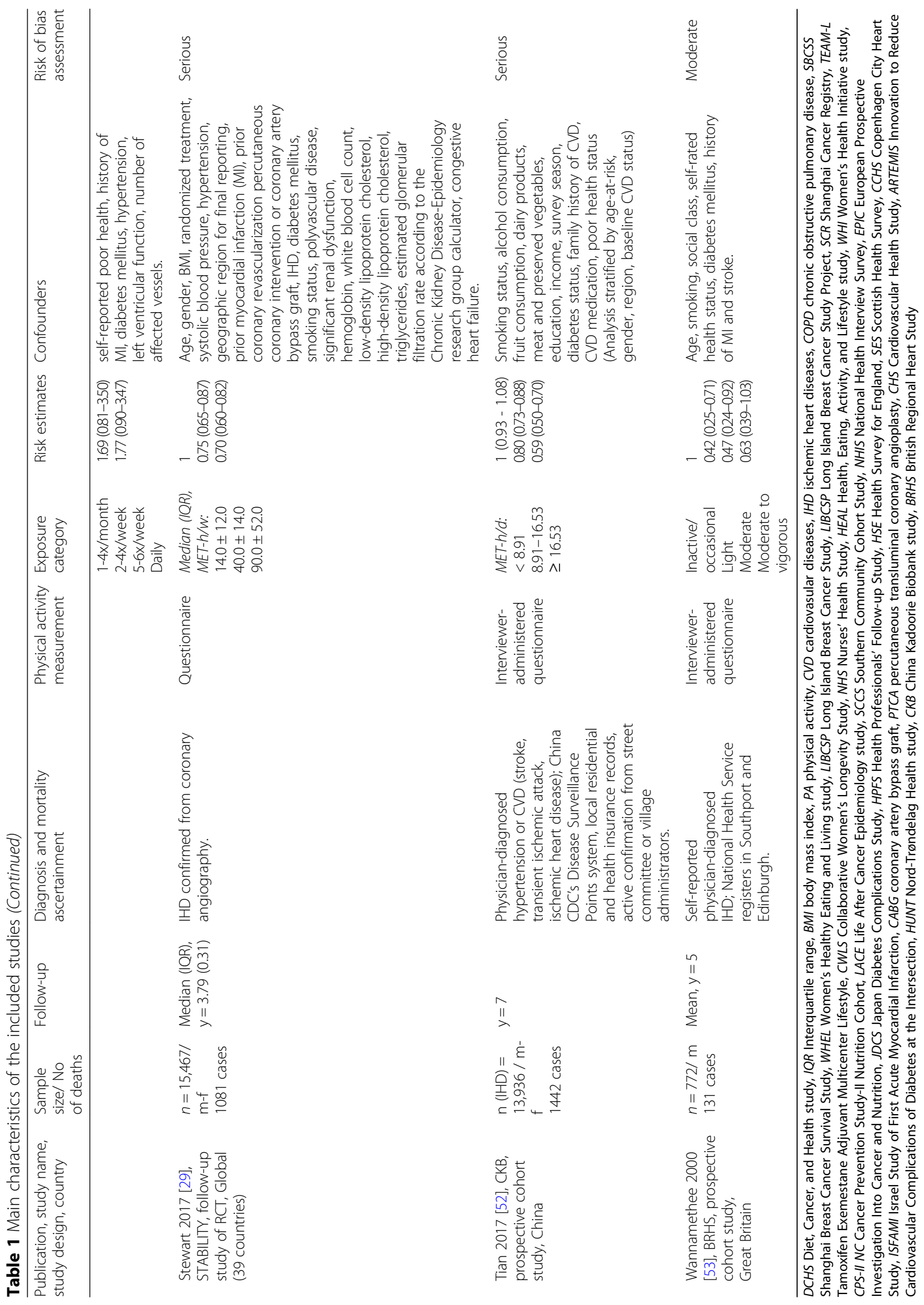




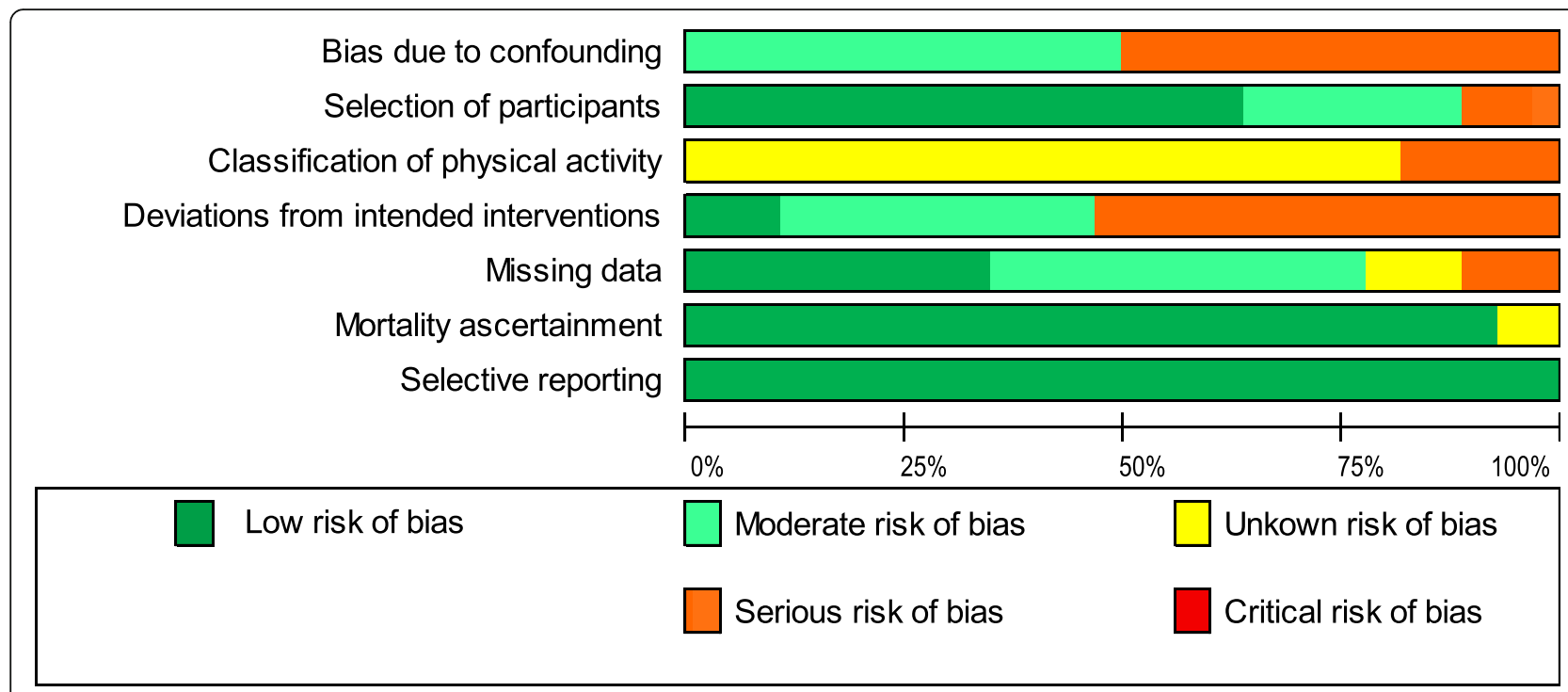

Fig. 2 Risk of bias graph

activity presented in MET-h/week and all-cause mortality ( $p$ for non-linearity $<0.001)$.

The curves for breast cancer, T2D and IHD show the steepest drop between 0 MET-h/week and 20 MET-h/ week; the COPD curve drops more markedly between 0 and $10 \mathrm{MET}$-h/week. After this, the curves flatten out. For T2D and COPD, significantly higher physical activity levels (up to around 90 MET-h/week) are also associated with further positive effects on mortality rates. For breast cancer, there appears a plateau with no additional effects on mortality with more than 45 MET-h/week.
For COPD, the curve could only be calculated up to 30 MET-h/week.

\section{Discussion}

In this systematic review and meta-analysis, higher levels of post-diagnosis physical activity were associated with a reduction in all-cause mortality in adults with breast cancer, T2D, IHD and COPD. Our dose-response metaanalysis highlights a non-linear association between physical activity levels and mortality characterized by (1) no threshold for the beneficial effect of physical activity

Table 2 Summary of findings

\begin{tabular}{|c|c|c|c|c|}
\hline \multicolumn{5}{|c|}{ Post-diagnosis physical activity and all-cause mortality for patients with breast cancer, COPD, type 2 diabetes and IHD } \\
\hline Outcome & $\begin{array}{l}\text { Relative effect per } 10 \\
\text { MET-h/week ( } 95 \% \mathrm{Cl})\end{array}$ & $\begin{array}{l}\text { № of } \\
\text { participants } \\
\text { (studies) }\end{array}$ & $\begin{array}{l}\text { Certainty of the } \\
\text { evidence (GRAD } \\
\text { E) }\end{array}$ & Informative statements \\
\hline $\begin{array}{l}\text { All-casue mortality } \\
\text { for breast cancer }\end{array}$ & $\begin{array}{l}\text { HR } 0.78(0.71 \text { to } \\
0.86)\end{array}$ & $\begin{array}{l}27,248(12 \\
\text { observational } \\
\text { studies) }\end{array}$ & $\oplus \bigoplus O O$ LOW $^{\mathrm{a}, \mathrm{b}, \mathrm{c}}$ & $\begin{array}{l}\text { The evidence suggests post-diagnosis physical activity results in a } \\
\text { slight reduction in all-cause mortality for individuals with breast } \\
\text { cancer. }\end{array}$ \\
\hline $\begin{array}{l}\text { All-cause mortality } \\
\text { for COPD }\end{array}$ & $\begin{array}{l}\text { HR } 0.70(0.45 \text { to } \\
1.09)\end{array}$ & $\begin{array}{l}4784(2 \\
\text { observational } \\
\text { studies) }\end{array}$ & $\begin{array}{l}\text { 円OOO VERY } \\
\text { LOW }{ }^{b, c, d, e, f}\end{array}$ & $\begin{array}{l}\text { The evidence is very uncertain about the effect of post-diagnosis } \\
\text { physical activity on all-cause mortality for individuals with COPD. }\end{array}$ \\
\hline $\begin{array}{l}\text { All-cause mortality } \\
\text { for IHD }\end{array}$ & $\begin{array}{l}\text { HR } 0.88(0.83 \text { to } \\
0.93)\end{array}$ & $\begin{array}{l}42,027(8 \\
\text { observational } \\
\text { studies) }\end{array}$ & $\oplus \oplus \circ \circ \mathrm{LOW}^{\mathrm{b}, c, g}$ & $\begin{array}{l}\text { The evidence suggests post-diagnosis physical activity results in a } \\
\text { slight reduction in all-cause mortality for individuals with IHD. }\end{array}$ \\
\hline $\begin{array}{l}\text { All-cause mortality } \\
\text { for type } 2 \\
\text { diabetes }\end{array}$ & $\begin{array}{l}\text { HR } 0.96(0.93 \text { to } \\
0.99)\end{array}$ & $\begin{array}{l}32,221(6 \\
\text { observational } \\
\text { studies) }\end{array}$ & $\oplus \oplus \circ \bigcirc$ LOW $^{\mathrm{a}, \mathrm{b}, \mathrm{c}}$ & $\begin{array}{l}\text { The evidence suggests post-diagnosis physical activity results in a } \\
\text { slight reduction in all-cause mortality for individuals with type } 2 \\
\text { diabetes. }\end{array}$ \\
\hline
\end{tabular}

\section{Explanations:}

aDowngraded by two levels since five studies were judged as serious risk of bias regarding confounding or selection bias based on ROBINS-I

${ }^{b}$ Downgraded by one level because although exposure was assessed in all studies using validated questionnaires, there were differences in the assessment and calculation of physical activity levels

'Upgraded by one level due to the dose-response gradient

${ }^{\mathrm{d} D o w n g r a d e d}$ by two levels since two studies were judged as serious risk of bias regarding confounding or selection bias based on ROBINS-I

e Downgraded by one level because the $95 \% \mathrm{Cl}$ includes the null value $(\mathrm{HR}=1.0)$ and includes important benefits $\mathrm{HR}<0.75$

fDowngraded by one level because publication bias could not be assessed due to limited number of studies $(<5$ studies)

${ }^{9}$ Downgraded by two levels since three studies were judged as serious risk of bias regarding confounding or selection bias based on ROBINS-I 


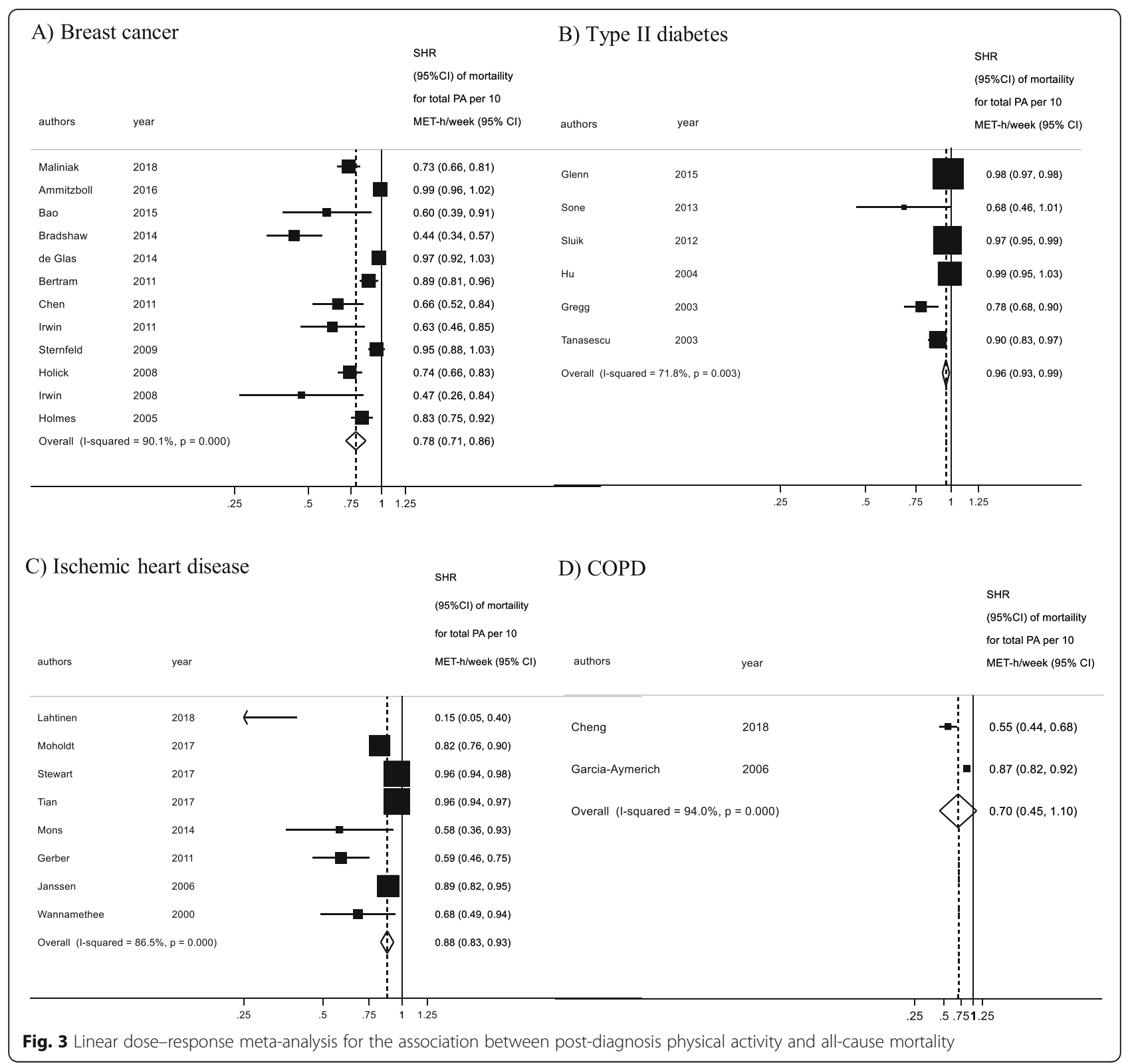

on mortality (i.e. even low levels of physical activity are beneficial for mortality rates compared to being physically inactive), (2) a non-linear curve, where the greatest difference in mortality rates occurs among inactive compared to minimally active individuals, and (3) for higher physical activity levels, the dose-response curves flatten out. Higher post-diagnosis physical activity levels may result in a slight reduction of all-cause mortality in breast cancer, T2D and IHD. The evidence is very uncertain about this effect in individuals with COPD.

The subgroup meta-analysis showed that longer follow-ups ( $\geq 10$ years) lead to higher reductions of SHR.
Although the effect size is higher for follow-ups that are 10 years or longer, there is an unexplained heterogeneity between the effects of physical activity within each subgroup. However, the unbalanced distribution of studies and the low overall number of studies for some subgroups make the interpretation difficult. Hence, it is uncertain whether the length of follow-up can explain the heterogeneity in the effect size. The reduction in mortality rates from physical activity were consistent and much the same after controlling for geographic areas (Asia, Europe, US, other), age (<60 years; $\geq 60$ years), number of cases $(<100,100-500)$ and the risk of bias (moderate; 


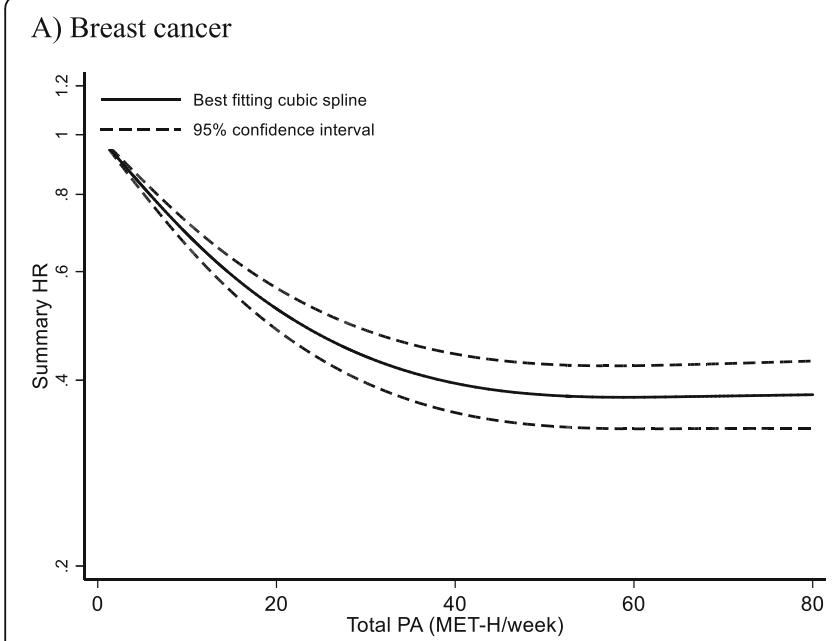

B) Type 2 diabetes

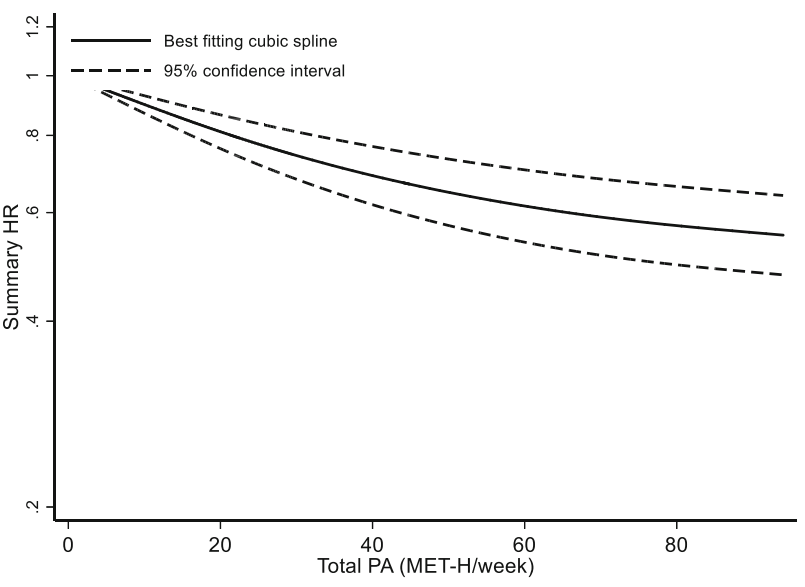

C) Ischemic heart disease

D) COPD
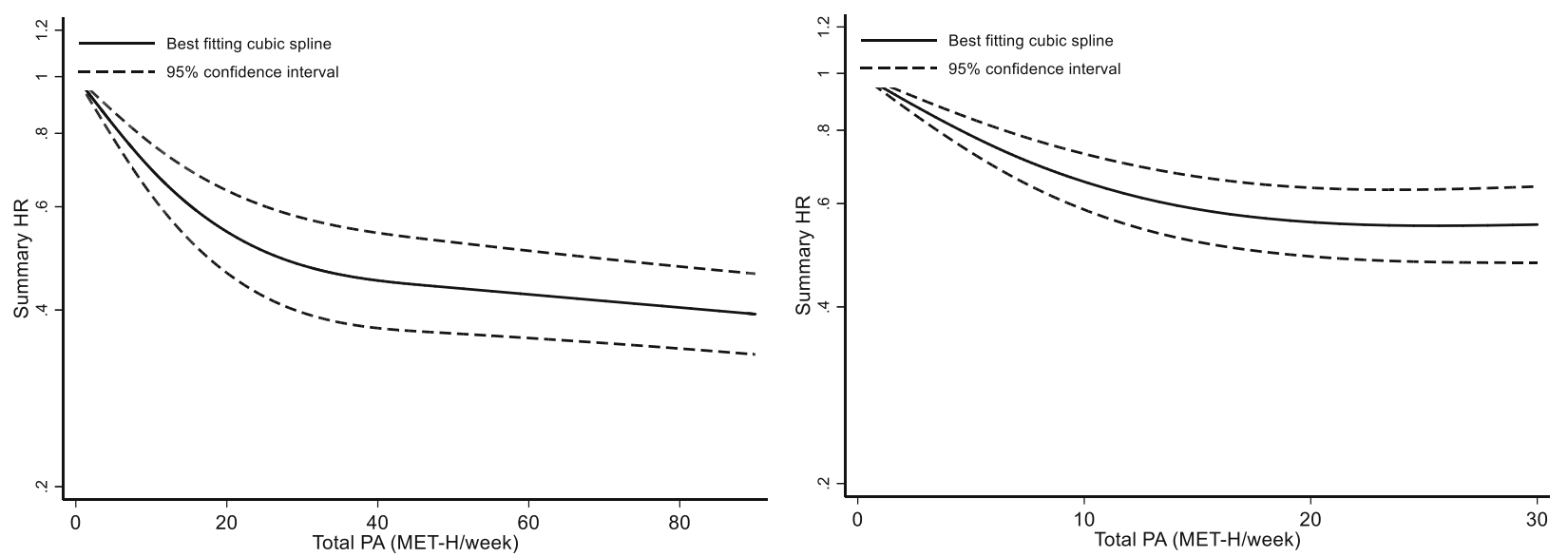

Fig. 4 Non-linear dose-response meta-analysis for the association between post-diagnosis physical activity and all-cause mortality. a) breast cancer $(n=12) ; \mathbf{b})$ type 2 diabetes $(n=6)$; $\mathbf{c})$ ischemic heart disease $(n=8)$; and $\mathbf{d})$ COPD $(n=2)$. The figure includes values up to 100 MET-h/week

serious). Due to a lack of studies, we were not able to determine dose-response relationships for physical activity and mortality in adults with low back pain, osteoarthritis, depressive disorder, lung cancer or stroke.

\section{Comparison with other studies}

Our findings confirm previous reviews and linear metaanalyses, which showed a general correlation between higher physical activity levels and lower mortality rates in adults with T2D [6] and breast cancer [7, 55, 56]. For women with breast cancer, the one available randomized controlled trial reported HR for mortality from 0.45 (95\% CI 0.21-0.97) for the physical activity intervention group compared to the control group [57]. However, since no specific activity levels are measured in this study, HRs are difficult to compare with the HR per each ten metabolic equivalent tasks hours calculated by us. Our linear meta-analysis reveals reductions of SHR per $10 \mathrm{MET}-\mathrm{h} /$ week that vary between the four NCDs. The lowest SHR reduction in our results was found in T2D
(4\%) - a somewhat weaker association than the 9.5\% reduction per one MET-h/day reported by Kodama et al. [6]. Findings may differ because of the differences in a) the outcome measured (all-cause mortality vs. causespecific mortality), b) in the physical activity categories (high vs. low vs dose-response analysis) and, c) in the included studies. We found medium reductions in IHD (12\%) and breast cancer (22\%) and the highest SHR reductions in COPD (30\%). Our applied non-linear dose-response-analysis extends and refines these previous linear analyses. The associations between different post-diagnosis physical activity levels and mortality for adults with NCDs are very similar to those recently developed for the general population $[9,58,59]$. Therefore, our results confirm the following main characteristics of the dose-response curves in the general population for adults with selected NCDs: (1) no threshold for the positive effect, (2) the most pronounced SHR reductions occurs between adults with little physical activity compared to those being physically inactive, and (3) no 
negative effects on mortality at higher volumes of physical activity.

For higher volumes of physical activity equivalent to an energy expenditure of more than five times the weekly recommended moderate-intensity physical activity of 150 min and more, the dose-response curve is less clearly defined. The dose-response curves of the US Physical Activity Guidelines Advisory Committee [9] does not include physical activity levels of more than 30 MET-hours/week. Ekelund et al. [59] include higher volumes of physical activity, stating that the maximal reductions in SHR were seen at about $24 \mathrm{~min} /$ day of moderate to vigorous physical activity or $375 \mathrm{~min} /$ day of light intensity; higher volumes of physical activity are associated with a slight reduction in their benefit on mortality rates. In our study, higher physical activity levels were associated with continuously small declines in mortality rates for IHD and T2D. For breast cancer, there is a point of maximum reduction of SHR at $55 \mathrm{MET}$ h/week with no additional benefits for higher physical activity levels. No data is available on higher physical activity levels for COPD.

In the total population, $70 \%$ of the maximum effect on mortality risk reduction is achieved at an energy consumption of 8.25 MET-h/week (equivalent to meeting the physical activity recommendations of 150 weekly minutes) [9]. Our results indicate that in adults with NCDs, this energy consumption is associated with about $40 \%$ of the maximum achievable reduction in mortality rates. Physical activity and both overall and cardiovascular mortality after stroke were connected through a dose-response relationship where $10 \mathrm{MET}-\mathrm{h} /$ day of physical activity produced 35-46\% reductions in SHR [52]. Although one study reported data on stroke patients [52], it was not sufficient to be included in the meta-analysis. For 4 NCDs (low back pain, osteoarthritis, depressive disorder, lung cancer), we were not able to find appropriate studies for our analysis. Thus, our findings confirm the research gap in the clinical populations already identified before [9].

\section{Strengths and limitations}

Our study has several strengths. Its main strength is the broad and comprehensive systematic literature search for 9 NCDs that have a high relevance for public health. For the first time, our work generates a broad overview of postdiagnosis physical activity and mortality for adults with NCDs. Another strength is the applied non-linear dose-response meta-analysis that enables precise statements regarding the effective dose of physical activity for reduced mortality rates. This information helps with the adaption or development of exercise recommendations for adults with NCDs. In addition, the use of the new ROBINS-I tool is a methodological strength that allows for a precise estimation of the risk of bias in different domains (e.g. bias in the measurement outcome, due to missing outcome data or due to deviation from intended interventions).
Despite its strengths, this systematic review and metaanalysis has limitations that should be acknowledged. First, at the outcome level of the study, the risk of bias in the measurement of physical activity in the original studies is unknown. All studies measured physical activity levels using self-reports. Compared to device-based measurements, self-reported measures are prone to over-reporting of one's physical activity levels [60]. If the over-reporting of physical activity already plays a role at low physical activity levels, the actual high relative reduction in mortality rates of somewhat physically active persons compared to inactive persons could be underestimated. Most of the studies have measured the level of physical activity only at one point in time, thus meaning that no information on changes over time is available. Moreover, different cut-off points were used by the single studies to classify the participants' levels of physical activity. This might lower the accuracy of the dose-response curves.

Second, the update of our literature search in August 2019 was conducted through Google Scholar and not through the original data bases (PubMed, Scopus and the Web of Science). This means that our original search strategy is not identical to the search update.

Third, at the study level, our findings are susceptible to bias derived from studies of an observational nature. Prospective observational cohort studies fail to provide conclusive evidence of a causal relationship between physical activity and mortality $[61,62]$. Our results might be affected by reverse causality, as patients may tend to adjust their physical activity level according to the disease severity and prognosis. Consequently, our analysis of cohort studies does not provide a conclusive answer as to whether the reported dose-response relationships between physical activity and mortality are actually causal or only correlative. According to Hill [63], however, our results increase the sense of confidence in a causal relationship because they display (1) a clear dose-response curve, (2) a strong association or high effect size, and (3) consistent results in different studies. For the diseases with low certainty of evidence (breast cancer, IHD, T2D) the persistence of our findings for longer follow ups of $>10$ years further strengthens our confidence in a causal relationship. Following the arguments from Hill [63], the additional proof of biological plausibility and evidence from experimental studies could further strengthen the confidence in causality. Bases on our results, we cannot exclude selection/survival bias, because inclusion of the participants in the studies depended on survival time after diagnosis of the disease. It is possible that participants with severe forms of the disease were already deceased or too ill to participate.

Fourth, at the review level and as reported in the study protocol [11], we did not consider the potential differences between different physical activity intensities (i.e. light vs moderate vs vigorous), between physical activity 
in different contexts (e.g. leisure time physical activity vs occupational physical activity) or the interaction between physical activity and sedentary behaviour. Furthermore, our analysis is likely to be affected by small-study effects and the small number of original studies available for the sensitivity analysis.

\section{Implications and future research}

Assuming causality, our findings have implications for adults with NCDs, physicians and other health professionals involved in physical activity promotion and exercise therapy, as well as healthcare decisionmakers and policymakers. First, our results bear importance for policymakers and those involved in public health issues. The results highlight the importance of a physically active lifestyle and support strategies to promote physical activity (e.g. the World Health Organization's Global Action Plan on Physical Activity) [64]. Second, for those creating physical activity guidelines, our findings may inform developments or updates on physical activity recommendations for adults with NCDs. Our findings reinforce low-dose physical activity recommendations that clearly demonstrate there is no minimum dose of physical activity and that effects on longevity occur at a volume of physical activity significantly below the recommended minimum dose of 150 min per week [65]. The " +10 minutes of physical activity per day" from Japan [66] or the "Every Step Counts" message from Germany [67] might be more feasible and efficient physical activity recommendations. Third, for physicians, our results illustrate the medical potential of exercise as medicine and encourage initiatives to anchor assess to and promotion of physical activity in routine medical care [68]. Fourth, for health professionals in the field of physical activity promotion, our results could lead to new targets for health-enhancing physical activity. Adults with NCDs are often rather physically inactive [69] and experience various barriers to physical activity, including time constraints and personal doubts about being able to participate in regular physical activity [70-72]. Completing at least $150 \mathrm{~min}$ of physical activity per week is considered by many to be overwhelming and unachievable. For adults with NCDs, non-threshold-based, lowdose physical activity recommendations could be effective while also being encouraging and easier to implement. Thus, low-dose physical activity recommendations would destroy many barriers in relation to an active lifestyle and increase the probability of success of interventions that promote physical activity.

The results also bear implications for future research. We identified a research gap: For 4 out of the 9 NCDs reviewed (lung cancer, depressive disorder, lung cancer, low back pain), there were no eligible studies available. Since the associations for post-diagnosis physical activity and mortality in adults with NCDs and the total population are different [8], future research should either conduct cohort studies on adults with NCDs or make a differentiation in the analysis of the total population between healthy people and those with an existing NCD. Furthermore, based on the considerable analyses of Ekelund et al. [59] in the overall population, future analyses for adults with NCDs should also consider different intensities and types of physical activity as well as the interaction between sedentary behaviour and physical activity. Finally, future studies should apply more reliable devicebased assessments of physical activity instead of questionnaires that are prone to over-reporting.

\section{Conclusion}

In conclusion, our systematic review and meta-analysis provides low certainty of evidence that higher levels of physical activity are associated with lower mortality rates in adults with T2D, IHD and breast cancer, while the certainty of evidence for COPD is very low. The shape of the dose-response curves are characterized by no threshold for the beneficial effect of physical activity on mortality meaning that any physical activity is better than none, and a regressive, non-linear dose-response pattern where the greatest difference in mortality rates occurs among inactive compared to minimally active individuals. There is no minimum dose of physical activity for life prolongation. Less physical activity than the recommended $150 \mathrm{~min}$ a week has life expectancy benefits for adults with a NCD. Our results encourage the development of low-dose physical activity recommendations for adults with NCDs.

\section{Supplementary information}

Supplementary information accompanies this paper at https://doi.org/1 0.1186/s12966-020-01007-5

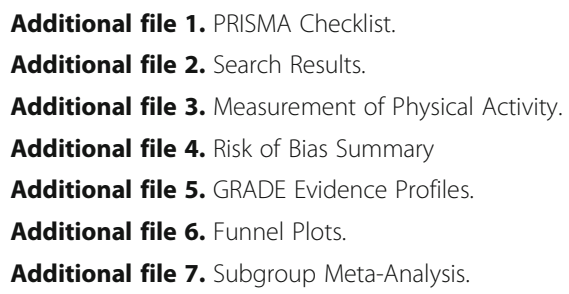

\section{Abbreviations}

NCD: Noncommunicable disease; T2D: Type 2 diabetes; MET: Metabolic equivalent task; COPD: Chronic obstructive pulmonary disease; IHD: Ischemic heart disease; SHR: Standard hazard ratio

\section{Acknowledgements}

We would like to thank Anna Ryan, Lukas Janz and Katja Bartsch for supporting the process of article screening. Many thanks to PD DR. Karim Abu-Omar for his valuable advice in the preparation of the final draft.

\section{Authors' contributions}

WG had the initial idea for this review; he is the guarantor of the study. WG, SS, EM, LM and KP designed the study, including the development of the selection criteria, the risk of bias assessment strategy, the search strategy and the data extraction strategy. EM and LM conducted the bias assessment. SS 
conducted the meta-analysis. WG, EM and SS prepared the first draft of this manuscript. All authors contributed substantially to the drafting of the final manuscript version. All authors have read and approved the final manuscript.

\section{Funding}

This research received no specific grant from any funding agency in the public, commercial or not-for-profit sectors. Open access funding provided by Projekt DEAL.

\section{Availability of data and materials}

Data (including the extracted contents from the searched articles) are available upon reasonable request from Dr. Wolfgang Geidl; mail: wolfgang. geidl@fau.de

\section{Ethics approval and consent to participate}

Not applicable.

\section{Consent for publication}

Not applicable.

\section{Competing interests}

The authors declare no conflict of interests.

\section{Author details}

'Department of Sport Science and Sport, Division Exercise and Health, Friedrich-Alexander University Erlangen-Nürnberg, Gebbertstraße 123b, 91058 Erlangen, Germany. ${ }^{2}$ Institute for Biometrics and Epidemiology, German Diabetes Center, Leibniz Center for Diabetes Research, Heinrich Heine University, Düsseldorf, Auf'm Hennekamp 65, 40225 Düsseldorf, Germany.

Received: 7 January 2020 Accepted: 29 July 2020

Published online: 26 August 2020

\section{References}

1. Pedersen BK, Saltin B. Exercise as medicine - evidence for prescribing exercise as therapy in 26 different chronic diseases. Scand J Med Sci Sports. 2015;25(Suppl 3):1-72. https://doi.org/10.1111/sms.12581.

2. Warburton DER, Bredin SSD. Health benefits of physical activity: a systematic review of current systematic reviews. Curr Opin Cardiol. 2017;32:541-56. https://doi.org/10.1097/HCO.0000000000000437.

3. Arem H, Moore SC, Patel A, Hartge P, Berrington de Gonzalez A, Visvanathan $\mathrm{K}$, et al. Leisure time physical activity and mortality: a detailed pooled analysis of the dose-response relationship. JAMA Intern Med. 2015. 175:959-67. https://doi.org/10.1001/jamainternmed.2015.0533.

4. Samitz G, Egger M, Zwahlen M. Domains of physical activity and all-cause mortality: systematic review and dose-response meta-analysis of cohort studies. Int J Epidemiol. 2011;40:1382-400. https://doi.org/10.1093/ije/dyr112.

5. U.S. Department of Health and Human Services. Physical activity guidelines for Americans. 2nd ed. Washington, DC: Department of Health and Human Services; 2018

6. Kodama S, Tanaka S, Heianza Y, Fujihara K, Horikawa C, Shimano H, et al. Association between physical activity and risk of all-cause mortality and cardiovascular disease in patients with diabetes: a meta-analysis. Diabetes Care. 2013;36:471-9. https://doi.org/10.2337/dc12-0783.

7. Li T, Wei S, Shi Y, Pang S, Qin Q, Yin J, et al. The dose-response effect of physical activity on cancer mortality: findings from 71 prospective cohort studies. Br J Sports Med. 2016;50:339-45. https://doi.org/10.1136/bjsports2015-094927.

8. Moore SC, Patel AV, Matthews CE, Berrington de Gonzalez A, Park Y, Katki $\mathrm{HA}$, et al. Leisure time physical activity of moderate to vigorous intensity and mortality: A large pooled cohort analysis. PLoS Med. 2012;9:e1001335. https://doi.org/10.1371/journal.pmed.1001335.

9. 2018 Physical Activity Advisory Committee. 2018 Physical activity guidelines advisory committee scientific report. Washington, DC: Department of Health and Human Services; 2018

10. Murray CJL, Vos T, Lozano R, Naghavi M, Flaxman AD, Michaud C, et al. Disability-adjusted life years (DALYs) for 291 diseases and injuries in 21 regions, 1990-2010: a systematic analysis for the global burden of disease study 2010. Lancet. 2012;380:2197-223. https://doi.org/10.1016/S01406736(12)61689-4.
11. Geidl W, Schlesinger S, Mino E, Miranda L, Ryan A, Bartsch K, et al. Doseresponse relationship between physical activity and mortality in people with non-communicable diseases: a study protocol for the systematic review and meta-analysis of cohort studies. BMJ Open. 2019;9:e028653. https://doi.org/10.1136/bmjopen-2018-028653.

12. Liberati A, Altman DG, Tetzlaff J, Mulrow C, Gotzsche PC, loannidis JPA, et al. The PRISMA statement for reporting systematic reviews and meta-analyses of studies that evaluate health care interventions: explanation and elaboration. PLoS Med. 2009;6:e1000100. https://doi.org/10.1371/journal. pmed. 1000100 .

13. Lahtinen $M$, Toukola T, Junttila MJ, Piira O-P, Lepojärvi S, Kääriäinen M, et al. Effect of changes in physical activity on risk for cardiac death in patients with coronary artery disease. Am J Cardiol. 2018;121:143-8. https://doi.org/ 10.1016/j.amjcard.2017.10.002.

14. Cheng SWM, McKeough Z, Alison J, Dennis S, Hamer M, Stamatakis E. Associations of total and type-specific physical activity with mortality in chronic obstructive pulmonary disease: a population-based cohort study. BMC Public Health. 2018;18:268. https://doi.org/10.1186/s12889-018-5167-5.

15. Sterne JAC, Hernán MA, Reeves BC, Savović J, Berkman ND, Viswanathan M, et al. ROBINS-I: a tool for assessing risk of bias in non-randomised studies of interventions. BMJ. 2016. https://doi.org/10.1136/bmj.i4919.

16. DerSimonian R, Laird N. Meta-analysis in clinical trials revisited. Contemp Clin Trials. 2015;45:139-45. https://doi.org/10.1016/..cct.2015.09.002.

17. Greenland S, Longnecker MP. Methods for trend estimation from summarized dose-response data, with applications to meta-analysis. Am J Epidemiol. 1992;135:1301-9.

18. Orsini N, Li R, Wolk A, Khudyakov P, Spiegelman D. Meta-analysis for linear and nonlinear dose-response relations: examples, an evaluation of approximations, and software. Am J Epidemiol. 2012;175:66-73. https://doi. org/10.1093/aje/kwr265.

19. Aune D, Greenwood DC, Chan DSM, Vieira R, Vieira AR, Navarro Rosenblatt DA, et al. Body mass index, abdominal fatness and pancreatic cancer risk: a systematic review and non-linear dose-response meta-analysis of prospective studies. Ann Oncol. 2012;23:843-52. https://doi.org/10.1093/annonc/mdr398.

20. Orsini N. From floated to conventional confidence intervals for the relative risks based on published dose-response data. Comput Methods Prog Biomed. 2010;98:90-3. https://doi.org/10.1016/j.cmpb.2009.11.005.

21. Borenstein M, Higgins JPT, Hedges LV, Rothstein HR. Basics of meta-analysis: I (2) is not an absolute measure of heterogeneity. Res Synth Methods. 2017; 8:5-18. https://doi.org/10.1002/jrsm.1230.

22. Egger M, Davey Smith G, Schneider M, Minder C. Bias in meta-analysis detected by a simple, graphical test. BMJ. 1997;315:629.

23. Sterne JAC, Harbord RM. Funnel plots in meta-analysis. Stata J. 2004;4:127-41.

24. Schünemann H, Brożek J, Guyatt G, Oxman A. GRADE handbook for grading quality of evidence and strength of recommendations. Updated December 2015. The GRADE Working Group, 2013. Available from: Https://gdt. guidelinedevelopment.org/app/handbook/handbook.html.

25. Guyatt G, Oxman AD, Akl EA, Kunz R, Vist G, Brozek J, et al. GRADE guidelines: 1. Introduction-GRADE evidence profiles and summary of findings tables. J Clin Epidemiol. 2011;64:383-94. https://doi.org/10.1016/j. jclinepi.2010.04.026.

26. Balshem $H$, Helfand $M$, Schünemann HJ, Oxman AD, Kunz R, Brozek J, et al. GRADE quidelines: 3. Rating the quality of evidence. J Clin Epidemiol. 2011; 64:401-6. https://doi.org/10.1016/j.jclinepi.2010.07.015.

27. Santesso N, Glenton C, Dahm P, Garner P. AkI EA, Alper B, et al. GRADE guidelines 26: informative statements to communicate the findings of systematic reviews of interventions. J Clin Epidemiol. 2020;119:126-35. https://doi.org/10.1016/j.jclinepi.2019.10.014.

28. Bertram C, Stefanick ML, Saquib N, Natarajan L, Patterson RE, Bardwell W, et al. Physical activity, additional breast cancer events, and mortality among early-stage breast cancer survivors: findings from the WHEL Study. Cancer Causes Control. 2011;22:427-35. https://doi.org/10.1007/s10552-010-9714-3.

29. Stewart RAH, Held C, Hadziosmanovic N, Armstrong PW, Cannon CP, Granger CB, et al. Physical activity and mortality in patients with stable coronary heart disease. J Am Coll Cardiol. 2017;70:1689-700. https://doi.org/ 10.1016/j.jacc.2017.08.017.

30. de Glas NA, Fontein DBY, Bastiaannet E, Pijpe A, de Craen AJM, Liefers G-J, et al. Physical activity and survival of postmenopausal, hormone receptorpositive breast cancer patients results of the tamoxifen exemestane adjuvant multicenter lifestyle study. Cancer. 2014;120:2847-54. https://doi. org/10.1002/cncr.28783. 
31. Glenn KR, Slaughter JC, Fowke JH, Buchowski MS, Matthews CE, Signorello $\mathrm{LB}$, et al. Physical activity, sedentary behavior and all-cause mortality among blacks and whites with diabetes. Ann Epidemiol. 2015;25:649-55. https://doi. org/10.1016/j.annepidem.2015.04.006.

32. Irwin ML, McTiernan A, Manson JE, Thomson CA, Sternfeld B, Stefanick ML, et al. Physical activity and survival in postmenopausal women with breast cancer: results from the Women's Health Initiative. Cancer Prev Res. 2011;4 522-9. https://doi.org/10.1158/1940-6207.CAPR-10-0295.

33. Hu G, Eriksson J, Barengo NC, Lakka TA, Valle TT, Nissinen A, et al. Occupational, commuting, and leisure-time physical activity in relation to total and cardiovascular mortality among Finnish subjects with type 2 diabetes. Circulation. 2004;110:666-73. https://doi.org/10.1161/01.CIR. 0000138102.23783 .94 .

34. Ammitzbø\|l G, Sogaard K, Karlsen RV, Tjønneland A, Johansen C, Frederiksen K, Bidstrup P. Physical activity and survival in breast cancer. Eur J Cancer. 2016;66:67-74. https://doi.org/10.1016/j.ejca.2016.07.010.

35. Bao P-P, Zhao G-M, Shu X-O, Peng P, Cai H, Lu W, Zheng Y. Modifiable lifestyle factors and triple-negative breast cancer survival: a populationbased prospective study. Epidemiology. 2015;26:909-16. https://doi.org/10. 1097/EDE.0000000000000373.

36. Bradshaw PT, Ibrahim JG, Khankari N, Cleveland RJ, Abrahamson PE, Stevens $J$, et al. Post-diagnosis physical activity and survival after breast cancer diagnosis: the Long Island Breast Cancer Study. Breast Cancer Res Treat. 2014;145:735-42. https://doi.org/10.1007/s10549-014-2966-y.

37. Chen X, Lu W, Zheng W, Gu K, Matthews CE, Chen Z, et al. Exercise after diagnosis of breast cancer in association with survival. Cancer Prev Res. 2011;4:1409-18. https://doi.org/10.1158/1940-6207.CAPR-10-0355.

38. Holick CN, Newcomb PA, Dietz-Trentham A, Ernstoff-Titus L, Bersch AJ, Stampfer MJ, et al. Physical activity and survival after diagnosis of invasive breast cancer. Cancer Epidemiol Biomark Prev. 2008;17:379-86. https://doi. org/10.1158/1055-9965.EPI-07-0771.

39. Holmes MD, Chen WY, Feskanich D, Kroenke CH, Colditz GA. Physical activity and survival after breast cancer diagnosis. JAMA. 2005;293:2479-86. https://doi.org/10.1001/jama.293.20.2479.

40. Irwin ML, Smith AW, McTiernan A, Ballard-Barbash R, Cronin K, Gilliland FD, et al. Influence of pre- and postdiagnosis physical activity on mortality in breast cancer survivors: the health, eating, activity, and lifestyle study. J Clin Oncol. 2008;26:3958-64. https://doi.org/10.1200/JCO.2007.15.9822.

41. Maliniak ML, Patel AV, McCullough ML, Campbell PT, Leach CR, Gapstur SM, Gaudet MM. Obesity, physical activity, and breast cancer survival among older breast cancer survivors in the Cancer Prevention Study-II Nutrition Cohort. Breast Cancer Res Treat. 2018;167:133-45. https://doi.org/10.1007/s10549-017-4470-7.

42. Sternfeld B, Weltzien E, Quesenberry CP Jr, Castillo AL, Kwan M, Slattery ML, Caan BJ. Physical activity and risk of recurrence and mortality in breast cancer survivors: findings from the LACE study. Cancer Epidemiol Biomark Prev. 2009;18:87-95. https://doi.org/10.1158/1055-9965.EPI-08-0595.

43. Gregg EW, Gerzoff RB, Caspersen CJ, Williamson DF, Narayan KMV. Relationship of walking to mortality among US adults with diabetes. Arch Intern Med. 2003;163:1440-7. https://doi.org/10.1001/archinte.163.12.1440.

44. Sluik D, Buijsse B, Muckelbauer R, Kaaks R, Teucher B, Johnsen NF, et al. Physical activity and mortality in individuals with diabetes mellitus: a prospective study and meta-analysis. Arch Intern Med. 2012;172:1285-95. https://doi.org/10.1001/archinternmed.2012.3130.

45. Sone H, Tanaka S, Suzuki S, Seino H, Hanyu O, Sato A, et al. Leisure-time physical activity is a significant predictor of stroke and total mortality in Japanese patients with type 2 diabetes: analysis from the Japan Diabetes Complications Study (JDCS). Diabetologia. 2013;56:1021-30. https:/doi.org/10.1007/s00125-012-2810-z.

46. Tanasescu M, Leitzmann MF, Rimm EB, Hu FB. Physical activity in relation to cardiovascular disease and total mortality among men with type 2 diabetes. Circulation. 2003;107:2435-9. https://doi.org/10.1161/01.CIR.0000066906.11109.1F.

47. Garcia-Aymerich J, Lange P, Benet M, Schnohr P, Antó JM. Regular physical activity reduces hospital admission and mortality in chronic obstructive pulmonary disease: a population based cohort study. Thorax. 2006;61:772-8. https://doi.org/10.1136/thx.2006.060145.

48. Gerber $Y$, Myers V, Goldbourt U, Benyamini Y, Scheinowitz M, Drory Y. Longterm trajectory of leisure time physical activity and survival after first myocardial infarction: a population-based cohort study. Eur J Epidemiol. 2011:26:109-16. https://doi.org/10.1007/s10654-010-9523-8.

49. Janssen I, Jolliffe CJ. Influence of physical activity on mortality in elderly with coronary artery disease. Med Sci Sports Exerc. 2006;38:418-7. https:// doi.org/10.1249/01.mss.0000191185.58467.be.
50. Moholdt T, Lavie CJ, Nauman J. Interaction of physical activity and body mass index on mortality in coronary heart disease: data from the NordTrøndelag Health Study. Am J Med. 2017;130:949-57. https://doi.org/10. 1016/j.amjmed.2017.01.043.

51. Mons $U$, Hahmann $H$, Brenner $H$. A reverse J-shaped association of leisure time physical activity with prognosis in patients with stable coronary heart disease: evidence from a large cohort with repeated measurements. Heart. 2014;100:1043-9. https://doi.org/10.1136/heartjnl-2013-305242.

52. Tian X, Du H, Li L, Bennett D, Gao R, Li S, et al. Fruit consumption and physical activity in relation to all-cause and cardiovascular mortality among 70,000 Chinese adults with pre-existing vascular disease. PLoS One. 2017. https://doi.org/10.1371/journal.pone.0173054.

53. Wannamethee SG, Shaper AG, Walker M. Physical activity and mortality in older men with diagnosed coronary heart disease. Circulation. 2000;102:1358-63.

54. Ainsworth BE, Haskell WL, Herrmann SD, Meckes N, Bassett DR, Tudor-Locke C, et al. 2011 compendium of physical activities: a second update of codes and MET values. Med Sci Sports Exerc. 2011;43:1575-81. https://doi.org/10. 1249/MSS.0b013e31821ece12.

55. Spei M-E, Samoli E, Bravi F, La Vecchia C, Bamia C, Benetou V. Physical activity in breast cancer survivors: a systematic review and meta-analysis on overall and breast cancer survival. Breast. 2019:44:144-52. https://doi.org/10. 1016/j.breast.2019.02.001

56. McTiernan A, Friedenreich CM, Katzmarzyk PT, Powell KE, Macko R, Buchner $D$, et al. Physical activity in cancer prevention and survival: a systematic review. Med Sci Sports Exerc. 2019;51:1252-61. https://doi.org/10.1249/MSS. 0000000000001937.

57. Soares Falcetta F, de Araújo Vianna Träsel H, de Almeida FK, Rangel Ribeiro Falcetta M, Falavigna M, Dornelles Rosa D. Effects of physical exercise after treatment of early breast cancer: systematic review and meta-analysis. Breast Cancer Res Treat. 2018;170:455-76. https://doi.org/10.1007/s10549-018-4786-y.

58. Wen CP, Wai JPM, Tsai MK, Yang YC, Cheng TYD, Lee M-C, et al. Minimum amount of physical activity for reduced mortality and extended life expectancy: a prospective cohort study. Lancet. 2011;378:1244-53. https:// doi.org/10.1016/S0140-6736(11)60749-6.

59. Ekelund U, Tarp J, Steene-Johannessen J, Hansen BH, Jefferis B, Fagerland MW, et al. Dose-response associations between accelerometry measured physical activity and sedentary time and all cause mortality: systematic review and harmonised meta-analysis. BMJ. 2019;366:14570. https://doi.org/10.1136/bmj.14570.

60. Craig R, Mindell J, Hirani V. Health survey for England. London: National Centre for Social Research; 2009.

61. Shiroma EJ, Lee I-M. Can we proceed with physical activity recommendations if (almost) no clinical trial data exist on mortality? $\mathrm{Br} J$ Sports Med. 2018;52:888-9. https://doi.org/10.1136/bjsports-2018-099185.

62. Wade KH, Richmond RC, Davey Smith G. Physical activity and longevity: how to move closer to causal inference. Br J Sports Med. 2018;52:890-1. https://doi.org/10.1136/bjsports-2017-098995.

63. Hill $A B$. The environment and disease: association or causation? Proc $R$ Soc Med. 1965:58:295-300

64. World Health Organization. Global action plan on physical activity 20182030: more active people for a healtier world. Geneva: World Health Organization; 2018.

65. World Health Organization. Global recommendations on physical activity for health. Geneva: World Health Organization; 2010.

66. Miyachi M, Tripette J, Kawakami R, Murakami H. " +10 min of physical activity per day": Japan is looking for efficient but feasible recommendations for its population. J Nutr Sci Vitaminol. 2015;61(Suppl):S7-9. https://doi.org/10. 3177/jnsv.61.S7.

67. Geidl W, Abu-Omar K, Weege M, Messing S, Pfeifer K. German recommendations for physical activity and physical activity promotion in adults with noncommunicable diseases. Int J Behav Nutr Phys Act. 2019; 17(1):12. https://doi.org/10.1101/19008953.

68. Lobelo F, Rohm Young D, Sallis R, Garber MD, Billinger SA, Duperly J, et al Routine assessment and promotion of physical activity in healthcare settings: a scientific statement from the American Heart Association. Circulation. 2018;137:e495-522. https://doi.org/10.1161/CIR. 0000000000000559.

69. Geidl W, Semrau J, Pfeifer K. Health behaviour change theories: contributions to an ICF-based behavioural exercise therapy for individuals with chronic diseases. Disabil Rehabil. 2014;36:2091-100.

70. Blaney JM, Lowe-Strong A, Rankin-Watt J, Campbell A, Gracey JH. Cancer survivors' exercise barriers, facilitators and preferences in the context of 
fatigue, quality of life and physical activity participation: a questionnairesurvey. Psychooncology. 2013;22:186-94. https://doi.org/10.1002/pon.2072.

71. Malone LA, Barfield JP, Brasher JD. Perceived benefits and barriers to exercise among persons with physical disabilities or chronic health conditions within action or maintenance stages of exercise. Disabil Health J. 2012;5:254-60. https://doi.org/10.1016/j.dhjo.2012.05.004.

72. Mulligan HF, Hale LA, Whitehead L, Baxter GD. Barriers to physical activity for people with long-term neurological conditions: a review study. Adapt Phys Activ. 2012;29:243-65. https://doi.org/10.1123/apaq.29.3.243.

\section{Publisher's Note}

Springer Nature remains neutral with regard to jurisdictional claims in published maps and institutional affiliations.

Ready to submit your research? Choose BMC and benefit from:

- fast, convenient online submission

- thorough peer review by experienced researchers in your field

- rapid publication on acceptance

- support for research data, including large and complex data types

- gold Open Access which fosters wider collaboration and increased citations

- maximum visibility for your research: over $100 \mathrm{M}$ website views per year

At BMC, research is always in progress.

Learn more biomedcentral.com/submissions 